\title{
Ideologia e política em Antônio Gramsci: aproximações teóricas às suas principais contribuições
}

\author{
Ideology and politics in Antonio Gramsci: theoretical \\ approaches to its main contributions
}

\author{
Paulo Roberto Felix dos Santos*
}

\begin{abstract}
Resumo - Diante do contexto atual de reordenamento das estratégias de hegemonia do capital, entende-se que esse processo traz consequências não só no plano estrutural, mas também na dimensão superestrutural. Assim, o presente artigo, de natureza teórica, busca problematizar, a partir da obra de Gramsci, as categorias ideologia e política, bem como a relação com os processos de constituição da hegemonia burguesa. Para essa análise, fez-se pesquisa bibliográfica, partindo de Cadernos do cárcere, cujos resultados apontaram para o caráter transversal que a ideologia e a política assumem na obra do autor, significando elementos fundamentais na constituição de uma nova vontade coletiva no seio da sociedade civil e sua relação com o Estado. Nesse processo, é imprescindível o papel que os aparelhos privados de hegemonia - sindicatos, movimentos sociais e partidos políticos - assumem na elaboração e efetivação de programa contra-hegemônico à sociabilidade do capital.
\end{abstract}

Palavras-Chave: ideologia; política; hegemonia; Gramsci.

\begin{abstract}
In view of the current context of reordering the strategies of capital hegemony, it is understood that this process has consequences not only in the structural plane, but also in the superstructural dimension. Thus, this theoretical article seeks to problematize, based on the work of Gramsci, the categories of ideology and politics, as well as their relation to the process of constitution of the bourgeois hegemony. For this analysis, a bibliographical research was carried out, starting with The Prison Notebooks, whose results pointed to the transversal character that ideology and politics assume in Gramsci's work. They mean fundamental elements in the constitution of a new collective will within civil society and its relation with the State. In this process, the role assumed by the private hegemonic apparatuses - unions, social movements, and political parties - in the elaboration and implementation of a counter-hegemonic program for the sociability of capital is indispensable.

Keywords: ideology; politics; hegemony; Gramsci.
\end{abstract}

\footnotetext{
* Doutorando em Serviço Social pela Universidade Federal do Rio de Janeiro e Professor Assistente do Departamento de Serviço Social da Universidade Federal de Sergipe. Membro do Grupo de Estudos e Pesquisas Marxistas da Universidade Federal de Sergipe (Gepem-UFS). Correspondência: DSS/CCSA/UFS. Avenida Marechal Rondon, S/n - Jardim Rosa Elze, São Cristóvão - Sergipe. CEP: 49100-000. Email: <fellix.ufs@gmail.com>.
} 


\section{Introdução}

As transformações societárias recentes têm desafiado a empreender análise substantiva dos fundamentos que engendram o movimento da realidade. É a partir desse desafio que se entende urgente o resgate e o debate construído pela tradição marxista acerca de rigorosa análise da realidade. A despeito de se encontrarem, nessa tradição, inúmeras referências que certamente podem ajudar a empreender leitura e análise ricas acerca da realidade contemporânea, destacam-se a contribuições do italiano Antônio Gramsci (1891-1937), cuja obra, mesmo que interrompida precocemente, ainda é viva e necessária para o enfrentamento de um conjunto de desafios interpostos pela sociabilidade capitalista.

Entre os diversos temas pelos quais transita o legado do autor, são notórias suas contribuições na discussão para a relação entre Estado e sociedade civil, bem como para a cultura e o papel dos intelectuais, almejando balizar elementos que permitam a construção de uma estratégia revolucionária - e suas particularidades no "Ocidente" e "Oriente". Percorrendo esse feixe de temas e preocupações sobre os quais se debruçou o autor, mostram-se fundamentais, para pensar os desafios do presente, as discussões empreendidas entre ideologia e política, sobretudo nas particularidades assumidas frente a mais uma crise do capital.

Parece inconteste que a crise a que se alude exige mudanças significativas do ponto de vista econômico, fato observado, mais recentemente, desde o fim dos anos de 1970, com os impactos da denominada "Reestruturação Produtiva" e sua consequente alteração nas esferas de produção e reprodução sociais (ANTUNES, 1998; HARVEY, 1998). Trata-se de uma crise sem precedentes e cujos limites de saneamento lhe impõem um caráter "crônico e estrutural" (MESZÁROS, 2009). Apesar das determinações econômico-estruturais que configuram esse processo, é fundamental compreender que ele também vem acompanhado de um reordenamento ídeopolítico em escala global'. Ante a esse contexto, não são raras as proposições de que se teria chegado ao "fim da história" (FUKUYAMA, 1992). Também nessa linha, na década de 1960, tem-se a proposição de Bell (1980) acerca do fim das ideologias, enunciada em The end of ideology (O fim da ideologia).

Após a derrocada da experiência do chamado "socialismo real" e a dissolução da União das Repúblicas Socialistas Soviéticas (URSS), em 1991, parece conformar uma ambiência apologética de esvaziamento de quaisquer alternativas frente ao capitalismo como sistema hegemônico. Foi em meio a esse novo contexto que ganharam maior reverberação os impactos das ideias,

\footnotetext{
${ }^{1}$ Conforme indica Mota $(2015$, p. 71$)$ : Numa conjuntura de crise, a reestruturação produtiva é uma iniciativa inerente ao estabelecimento de um novo equilíbrio instável, que tem como exigência básica a reorganização do papel das forças produtivas na recomposição do ciclo de reprodução do capital, tanto na esfera da produção como na das relações sociais.
} 


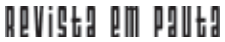

\} IDEOLOGIA E POLÍTICA EM ANTÔNIO GRAMSCI: APROXIMAÇÕES TEÓRICAS - SANTOS, P. R. F. \}

DOI $10.12957 /$ REP.2017.30376

postuladas até os dias atuais, de Fukuyama (1992), para quem o capitalismo e a democracia burguesa constituem o coroamento da história da humanidade, não havendo alternativas de realidade para além das determinações capitalistas.

Essas acepções infligem duro golpe nas concepções de ideologia e política como elementos fundamentais na estruturação do conjunto das lutas sociais, com consequentes desdobramentos na análise da realidade contemporânea. Nessas condições, essas categorias são retiradas - ou pelo menos vem-se buscando, em vão, retirá-las - da cena pública, por serem entendidas como discussão démodé. Nesses termos, falar em ideologia (ou ideologias) na contemporaneidade adquire conotação essencialmente pejorativa. Trata-se de um processo que Lukács (2011), acertadamente, denominou de "nova ideologia da desideologização". Do mesmo modo, concorda-se com lasi (2011, p. 87), para quem "podemos ver o quanto de hipocrisia existe na afirmação peremptória sobre o 'fim das ideologias'. Elas não apenas não morreram como se reforçaram no disfarce que lhes cabe, 'como não ideologias'".

No segundo caso, a política passa a ser reduzida à melhor forma de aperfeiçoamento da ordem vigente. Ora, o raciocínio é de que se chegou ao ápice da humanidade e, portanto, ao Fim da História, não havendo possibilidades de inclinações extremadas à direita ou à esquerda, sob pena de cair nos horrores do totalitarismo; desse modo, cumpre tão somente melhorar o que está posto. Não há outra possibilidade senão a de se corrigirem as "falhas naturais" do modo de produção capitalista, tornando-o mais "humano" e "socialmente responsável".

Essas ideias ganham força num movimento que se pauta em uma reestruturação no campo da ideologia e da política, condicionadas, em última instância, pelas determinações estruturais que configuram o atual modelo de acumulação do capital. Se a hipótese estiver correta, o contexto contemporâneo não tem apontado para o fim da ideologia e/ou da política, como aporte fundamental de capilarização de domínio e direção da burguesia sobre os demais seguimentos da sociedade. Pelo contrário, tem-se assistido a um profundo ataque ideológico travestido de não ideologia. Para situar os desafios do tempo presente, pode-se pensar, por exemplo, na apologia da famigerada proposta denominada "Escola Sem Partido" ${ }^{2}$, isso para ficar em apenas um dos fantasmas ídeo-políticos que se têm instaurado numa conjuntura de profunda ofensiva conservadora. Nesse sentido, não só subsiste uma clara luta política e ideológica, mas estas se aprofundam num contexto de acirramento da luta de classes.

\footnotetext{
${ }_{2}^{2}$ Apesar de serem vários projetos nas instâncias federativas, remetemos a dois especificamente que tramitam no Congresso Nacional: o PL 867/2015, de autoria de Izalci Lucas (PSDB), na Câmara dos Deputados; outro, no Senado Federal, o PL 193/2016, apresentado Magno Malta (PR-ES). A grosso modo, é uma proposta de (des)ideologização do ambiente escolar com um (não menos contraditório) claro cariz ideológico conservador.
} 


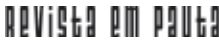

\} IDEOLOGIA E POLÍTICA EM ANTÔNIO GRAMSCI: APROXIMACCÕES TEÓRICAS - SANTOS, P. R. F. \} DOI 10.12957/REP.2017.30376

É nessa perspectiva que, neste texto, tem-se por objetivo problematizar as acepções de ideologia e de política, bem como sua importância para compreensão da realidade contemporânea, a partir dos estudos de um dos mais importantes pensadores da tradição marxista. Faz-se essa escolha por entender que se trata de um dos mais influentes teóricos e militantes que abordaram as temáticas em questão, situando-se como fundamental no renascimento do marxismo do século XX. Ademais, Gramsci (2007) problematizou de forma magistral o entrelaçamento das esferas da ideologia e da política, sobretudo, a partir do desenvolvimento de sua teoria da hegemonia.

Expressando o movimento de pesquisas ${ }^{3}$ realizadas nos últimos anos acerca da obra do autor italiano, apresentam-se, a partir de artigo de natureza teórico-bibliográfica, alguns resultados a que se chegou até aqui, de modo a explicitar a importância das categorias de ideologia e política na obra de Gramsci. Para fundamentar o presente artigo tomou-se por base, fundamentalmente, a obra de maturidade do autor, a partir das discussões desenvolvidas em Cadernos do cárcere. Optou-se por esse caminho por entender que lá se encontram importantes apontamentos acerca dos temas aqui problematizados. Certamente, o caráter inconcluso e pouco sistemático do material pode - e com muita frequência tem ocorrido - gerar as mais diversas interpretações. Por isso, buscou-se delinear os argumentos que apresentam determinado consenso acerca da obra do autor, para sustentar a argumentação a partir do diálogo com reconhecidos estudiosos da sua obra.

Na primeira parte deste texto, demonstra-se como Gramsci aborda a questão da ideologia, sobretudo a partir de uma concepção histórico-objetiva, enriquecendo com novas determinações a clássica definição presente na obra marxiana ${ }^{4}$. Ao resgatar os fundamentos da categoria ideologia, o pensador sardo oferece importantes reflexões acerca do contexto contemporâneo, expressando limites, mas também possibilidades concretas.

Em seguida, na segunda parte, apresentam-se elementos que prefiguram uma estreita relação entre as noções de ideologia e política na acepção gramsciana. Nesse esforço, tenta-se demonstrar como essas categorias se alinham tendo como eixo articulador a noção de hegemonia. Por outro lado, também se buscou apontar o caráter histórico dessas categorias, que, como tais, não estão dadas a priori, mas, ao contrário, requerem intencionalidades por parte dos sujeitos que as operam, sempre respondendo a um contexto sócio-histórico determinado.

\footnotetext{
${ }^{3}$ Desde 2014, o autor deste artigo vem se dedicando a empreender estudos e pesquisas relacionadas à obra de Gramsci. A primeira iniciativa se deu num grupo de estudos sobre o pensamento de Gramsci, junto ao Programa de Educação Tutorial/Serviço Social da UFS. Depois realizou uma pesquisa de iniciação científica, que contou com a apoio da Copes/UFS, com o intento de perquirir a discussão da ideologia na obra do autor.

${ }^{4}$ Não há consenso sobre se existe uma única concepção de ideologia em Marx. Há a tese de que ideologia é sempre apresentada com uma noção pejorativa, como aponta lasi (2014), por exemplo, e que diverge, a nosso ver, da perspectiva apontada por Mészáros (2009) e Coutinho (2008). Sem entrar nessa seara, buscou-se registrar o potencial heurístico do caráter próprio apresentado por Gramsci acerca dessa categoria.
} 
Com isso, objetiva-se apontar elementos que podem permitir a melhor clarificação de alguns desafios hodiernos, bem como salientar a necessidade de adensar espaços de construção contra-hegemônicos. Desse modo, intenta-se possibilitar a construção de nova vontade coletiva, que se expresse verdadeiramente nas demandas pautadas pelos subalternos, e que, articulada com mudanças estruturais, possa trazer à ordem do dia a necessidade de superação da sociabilidade vigente.

\section{Ideologia: fundamento histórico-objetivo em Gramsci}

É corrente no marxismo o uso da categoria ideologia, com tendência a apreendê-la a partir de uma dimensão negativa e mecânica como "falsa consciência", desde a aquisição de ideias falsas ${ }^{5}$. Entende-se que, na obra de Gramsci, ao contrário desse uso habitual, existe decidida revalorização da categoria ideologia, a partir de uma inovação no interior do paradigma marxiano. A trilha que leva o autor a desenvolver sua acepção da categoria ideologia é inspirada pela crítica à superestrutura em suas múltiplas expressões. Mas não se trata de uma crítica que cinde a dimensão superestrutural do terreno das estruturas. Ao contrário, essas esferas são pensadas enquanto determinação dialética de interações recíprocas. O conjunto dessas determinações ganha, em Gramsci (2007, p. 250), a nomenclatura de Bloco Histórico, "[...] isto é, o conjunto complexo e contraditório das superestruturas [que] é o reflexo do conjunto das relações sociais de produção".

Nessa direção, para Gramsci (2007, p. 238), a definição de Bloco Histórico comporta o fato de que "[...] as forças materiais são o conteúdo e as ideologias são a forma". Ainda adverte o autor que a distinção entre forma e conteúdo é puramente didática, "[...] já que as formas materiais não seriam historicamente concebíveis sem forma e as ideologias seriam fantasias individuais sem as forças materiais" (GRAMSCI, 2007, p. 238). É nessa perspectiva que o filósofo italiano constrói a sua "teoria da ideologia".

Conforme argumenta Liguori (2007, p. 78), é muito provável que Gramsci não tenha tido acesso ao conjunto de obras marxianas que nos leva hoje ao "lugar de nascimento do marxismo de ideologia na sua conotação negativa", sobretudo o conjunto de formulações presentes em A ideologia alemã, que remete à noção de ideologia como falsa consciência. Segundo Konder (2002, p. 106), o próprio Gramsci, ao se referir ao caráter das ideologias no âmbito da filosofia da práxis, aponta que: "Para Marx, as 'ideologias' não têm nada de ilusão e aparência; são uma realidade objetiva e operante, mas não são a mola da história, eis tudo".

\footnotetext{
${ }^{5}$ Trata-se de uma concepção equivocada, da qual Gramsci não partilha. Não corresponde a um mero acúmulo de ideias falsas. Se assim o fosse, a alternativa seria bem mais simples do que parece ser. Dever-se-ia, tão somente, substituir essas "ideias falsas" por outras "ideias verdadeiras". As ideias se colocam de forma invertida porque se vive uma realidade invertida; trata-se de uma determinação objetiva, e não de um desvio cognitivo.
} 


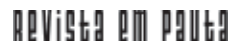

\} IDEOLOGIA E POLÍTICA EM ANTÔNIO GRAMSCI: APROXIMAÇÕES TEÓRICAS - SANTOS, P. R. F. \} DOI $10.12957 /$ REP.2017.30376

É importante notar que se torna evidente, para o filosofo italiano, que as ideologias não se constituem como a última determinação do desenvolvimento da história, ou, como ele mesmo escreve, "não são a mola da história". Isso permite apontar para os limites da própria ideologia enquanto categoria histórica, inserida, portanto, no conjunto da totalidade social. Assim, não se pode depreender da obra desse pensador uma concepção ingênua no poder que tem a ideologia de, per si, transformar todo o conjunto da sociedade. Qual seria, então, o limite das ideologias?

Gramsci (2013) situa essa zona limítrofe a partir de suas determinações históricas e sociais. Seu limite situa-se no terreno sócio-objetivo em que são geradas. Por isso, afirma o autor que: "Não são as ideologias que criam a realidade social, mas é a realidade social, na sua estrutura produtiva, que cria as ideologias" (GRAMSCI, 2013, p. 238). Há, nesse movimento, clara demarcação do momento predominante (übergreifenden moment) na dinâmica entre estrutura e superestrutura. Ainda que as ideologias tenham como lócus de intervenção a esfera da superestrutura, seu lugar de origem e, portanto, seus fundamentos só podem ser conhecidos no conjunto da estrutura produtiva da sociedade, na forma pelas quais as classes se relacionam na produção social das suas existências.

Partindo da relação de determinações recíprocas entre objetividade e subjetividade, toda a concepção de ideologia presente nas obras de Gramsci não se reduz a uma definição subjetivista, como se essas ideias estivessem descoladas de uma dada base material. Situando essa determinação especificamente na obra de Gramsci, Liguori (2007, p. 82) aponta que o autor italiano "[...] está sempre atento à necessidade de conduzir uma luta em duas frentes, contra o 'economicismo' por um lado, e contra o 'ideologismo' por outro [...]". Nesses termos, a inovação trazida por Gramsci em relação à ideologia demonstra a tentativa do autor de "livrar" o marxismo de sua época da tendência a uma visão determinista, como se os fenômenos ideológicos fossem constituídos como um epifenômeno da estrutura, reproduzindo imediata e mecanicamente as relações de dominação de classe.

Por outro lado, diferentemente de uma suposta interpretação subjetivista na obra do pensador sardo, tem-se a clareza de que este, ao situar a ideologia num processo de interações dialéticas entre subjetividade e objetividade, compreendendo esta última como determinação em última instância no campo das superestruturas, apresenta uma concepção objetiva da ideologia. Para Coutinho (2008), Gramsci "se recusa" a analisar a ideologia de um ponto de vista estritamente gnosiológico, ou seja, apenas como "falsa consciência", em contraste com "consciência verdade" (ciência). Para o autor, em suas formulações sobre a ideologia, Gramsci a apresenta como "força real, que altera e modifica a vida humana, mesmo quando seus conteúdos cognitivos não correspondam à reprodução da realidade" (COUTINHO, 1999, p. 113-114). 


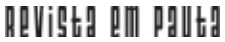

\} IDEOLOGIA E POLÍTICA EM ANTÔNIO GRAMSCI: APROXIMAÇÕES TEÓRICAS - SANTOS, P. R. F. \}

DOI $10.12957 /$ REP.2017.30376

No que essa acepção contribui para pensar a atualidade? A conclusão a que possivelmente teria chegado Gramsci permite compreender que mesmo ideias falsas ou verdadeiras, do ponto de vista gnosiológico, podem vir a ser ideologia, ao penetrarem nas relações sociais de modo a se pôr como se constituíssem verdade inquestionável. Nessa linha, parece que Gramsci se mantém fiel ao seu mestre, Marx (2013, p. 157), quando este aponta que: a "teoria se torna força material quando se apodera das massas". Quando alguém diz, por exemplo, que valores como egoísmo e competição fazem parte da "natureza humana" ${ }^{\prime}$, parece ser quase impossível questionar esses postulados, dado o caráter de valor absoluto que essas ideias assumem.

Todavia, para Gramsci, não há uma noção homogênea e unívoca em torno da categoria ideologia. Ao discorrer sobre a noção de ideologia, Gramsci (2013, p. 237 - grifos nossos) adverte que: "É necessário, por conseguinte, distinguir entre ideologias historicamente orgânicas, isto é, que são necessárias a uma determinada estrutura, e ideologias arbitrárias, racionalísticas, 'voluntaristas'". No primeiro caso, o autor faz remissão ao conjunto de ideias agregadas e sistemáticas num determinado processo. Para ele, "Enquanto são historicamente necessárias, as ideologias têm uma validade que é validade 'psicológica': elas 'organizam' as massas humanas, formam o terreno no qual os homens se movimentam, adquirem consciência de sua posição, lutam etc." (GRAMSCI, 2013, p. 237).

Ademais, cabe retomar a validade que as ideologias orgânicas têm para Gramsci (ano) ao organizarem as massas e formarem o terreno no qual, segundo ele, os homens se movimentam e adquirem consciência de sua posição e, a partir daí, lutam. Essa posição defendida pelo autor é explícita remissão ao trecho do Prefácio à crítica da economia política, em que Marx (2008 p. 48 - grifos nossos) argumenta que:

Quando se consideram tais transformações [da base material sobre a superestrutura] convém distinguir sempre a transformação material das condições econômicas de produção - que podem ser verificadas fielmente com a ajuda das ciências físicas e naturais - e as formas jurídicas, políticas, religiosas, artísticas ou filosóficas, em resumo, as formas ideológicas sob as quais os homens adquirem consciência do conflito e o levam até o fim.

Em relação ao que Gramsci (2013) considera como ideologias "arbitrárias", estas não podem criar mais do que "movimentos" individuais, polêmicas etc. Trata-se de um conhecimento assistemático e desagregado. Apesar disso, não significa que não tenham validade. Sua diferenciação das ideologias enquanto "historicamente orgânicas" e "arbitrárias" corresponde,

\footnotetext{
${ }^{6}$ Como lembra Gramsci $(2007$, p. 56), há uma natureza humana, mas que é dinâmica, diferente da vulgata posição recorrente. Para o autor, "[...] a natureza humana é o conjunto das relações sociais historicamente determinadas, ou seja, um fato histórico verificável, dentro de certos limites com os métodos da filologia e da crítica".
} 
tão somente, às suas determinações de forma e conteúdo, mas não de critério de validade.

$\mathrm{Na}$ acepção gramsciana, as ideologias podem-se constituir em formas e qualidades diferenciadas, sobretudo no que tange a seu nível de coesão, conseguindo se expressar nas esferas do senso comum, do folclore, da religião ou mesmo no campo da filosofia. Esta última, como forma de expressão de ideologia, tem relação conjugada, na medida em que se encarrega de alimentar uma dada concepção de mundo. Além disso, a filosofia pode se encarregar de lançar o ponto crítico dessa mesma concepção. A concepção de mundo dada pela filosofia faz refletir sobre a incidência ideológica de qualquer classe, seja ela burguesa ou proletária, conforme argumenta Gramsci (2013).

A filosofia se entrelaça com a ideologia no momento em que uma participa da história da outra. Sem a ação ideológica, não existe possibilidade de introduzir a ação filosófica nesse âmbito. De acordo com Gramsci (2013, p. 325):

A história da filosofia tal como é comumente entendida, isto é, como história das filosofias dos filósofos, é a história das tentativas e das iniciativas ideológicas de uma determinada classe de pessoas para mudar, corrigir, aperfeiçoar as concepções de mundo existentes em todas as épocas determinadas e para mudar, portanto, as normas de conduta que Ihes são relativas e adequadas, ou seja, para mudar a atividade prática em seu conjunto.

Acerca da natureza da filosofia, sabiamente, Gramsci (2013, p. 93) adverte que: "É preciso destruir o preconceito, muito difundido, de que a filosofia é algo muito difícil pelo fato de ser a atividade intelectual própria de uma determinada categoria de cientistas especializados ou de filósofos profissionais e sistemáticos". Qual o caminho para começar a implodir esse "preconceito" acerca da noção que se tem de filosofia? Para o autor, o primeiro passo é compreender "[...] que todos os homens são 'filósofos', definindo os limites e as características desta 'filosofia espontânea'" (GRAMSCI, 2013, p. 93). Portanto, todos os homens seriam filósofos porque todos partilham de uma dada visão de mundo, conscientes ou não. Essa marca do que o autor denominou de "filosofia espontânea" se expressaria na linguagem, no senso comum, no bom senso e na "religião popular", que ele aponta como sendo todo o sistema de crenças, superstições, opiniões, modos de ver e de agir que se manifestam naquilo que geralmente se conhece por "folclore" (GRAMSCl, 2013).

Para Gramsci (2013, p. 94), é fundamental a crítica das formas de filosofia espontânea para situar o indivíduo com seu gênero, vez que "[...] a crítica à própria concepção do mundo, significa torná-la unitária e coerente e elevá-la até o ponto atingido pelo pensamento mundial mais evoluído". Nesse sentido, o espaço do cotidiano se expressa como campo em disputa, 


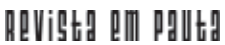

\} IDEOLOGIA E POLÍTICA EM ANTÔNIO GRAMSCI: APROXIMAÇÕES TEÓRICAS - SANTOS, P. R. F. \}

DOI 10.12957/REP.2017.30376

terreno onde se confrontam as lutas em torno de projetos societários. É nesse espaço que os sujeitos se expressam da forma mais imediata e necessária possível e, portanto, partilham de diversas visões de mundo em contraposição. O cotidiano é, assim,

[...] o local do choque dos projetos classistas que buscam impor sua visão e controle sobre os demais, é o espaço da luta de classes. Por isso, Gramsci fala da necessidade para as classes subalternas de construir e a praticar a crítica dos discursos tendencialmente hegemônicos dos dominantes. Isto não é, contudo, suficiente. Faz-se necessário destruir as condições sociais que tornam possíveis aqueles projetos. (DIAS, 2006, p. 58).

Nesse processo de crítica à vida cotidiana, Gramsci (2013) se empenha na defesa da criação de uma nova moral e cultura. Daí a importância da filosofia como campo de construção de uma concepção de mundo coerente. Todavia, há que se ressaltar que, apesar dessa característica, nem toda filosofia se coloca numa perspectiva crítica. Como salienta o autor: "[...] não existe filosofia em geral: existem diversas filosofias ou concepções de mundo, e sempre se faz uma escolha entre elas" (GRAMSCI, 2013, p. 93). Dadas as diversas filosofias, Gramsci (2013, p. 204) se empenha em demonstrar o caráter inovador trazido pelo que denomina de filosofia da práxis ${ }^{7}$, uma reformulação do hegelianismo, que ele define como:

[...] uma filosofia liberada (ou que busca liberar-se) de qualquer elemento ideológico unilateral e fanático, é a consciência plena das contradições, na qual o próprio filosofo, entendido individualmente ou como um grupo social global, não só compreende as contradições, mas coloca a si mesmo como elemento da contradição, eleva este elemento a princípio de conhecimento e, consequentemente, de ação.

Ela é a expressão mais completa das contradições históricas porque é consciente, o que também a torna ligada à necessidade e não à liberdade, a qual não existe e ainda não pode existir historicamente. Filosofia da práxis não é um pensamento puro ou um esquema gnosiológico abstrato, que cria idealmente as coisas e os fatos; é "ato impuro", atividade concreta, histórica, fundada em relações abertas, dinâmicas e dialéticas do homem com a natureza, da vontade humana com as estruturas econômicas, dos projetos políticos com as cristalizações culturais. Dessa maneira,

[...] deduz-se daí, também, que o caráter da filosofia da práxis é sobre tudo o de ser uma concepção de massa e de massa que opera unitariamente, isso é, que tem normas de conduta não só universais em ideia, mas também 'generalizadas' na realidade social. (GRAMSCI, 2013, p. 340$)$.

\footnotetext{
7 Trata-se de um pseudônimo utilizado por Gramsci para substituir a expressão "marxismo", em face da censura que sofria nos anos do cárcere.
} 
Convém destacar que a ideologia, bem como a filosofia, não são construções em abstrato; antes, são momentos atravessados pela política. Por diversas passagens, em Cadernos do cárcere, Gramsci (2007; 2013) apontou que a política - no seu sentido amplo em relação à dimensão restrita de "ciência política" - atravessa várias dimensões da sociabilidade. É, portanto, dessa indissociabilidade entre ideologia e política que trataremos no item a seguir.

\section{Ideologia e política: a construção da hegemonia}

De início, cumpre apresentar a diferenciação que o autor sardo faz entre o que denomina grande política e pequena política. Assim, diz ele:

A grande política compreende as questões ligadas à fundação de novos Estados, à luta pela destruição, pela defesa, pela conservação de determinadas estruturas orgânico-sociais. A pequena política compreende as questões parciais e cotidianas que se apresentam no interior de uma estrutura já estabelecida em decorrência de lutas pela predominância entre as diversas frações de uma mesma política. (GRAMSCI, 2013, p. 21).

Comece-se pelo final. Quando Gramsci (2013) aborda o que denomina de "pequena política", ele se refere aos conchavos de corredor, discussão sobre questões menores e de interesses particularistas, nada distante do que se tem observado no cenário político atual - no sentido de políticoparlamentar - brasileiro, quando se confronta com o lamaçal de corrupção, balcão de cargos na gestão estatal e instrumentalização da barganha política. Nesses termos, quem fizer uma leitura mais apressada do trecho em que Gramsci (2013) aborda essa questão pode ter uma compreensão também apressada, donde se pode derivar uma apreensão de desqualificação ou de consideração de menor relevância da esfera da pequena política. Esquecemse, todavia, que, na linha seguinte ao trecho acima citado, o autor registra que: "[...] é grande política tentar excluir a grande política do âmbito interno da vida estatal e reduzir tudo a pequena política" (GRAMSCI, 2013, p. 21).

Não há, portanto, abissal separação entre essas duas esferas. Sabese que a conjuntura, especialmente no que tange à realidade brasileira, tem-se pautado por profundo descrédito em torno do espaço político - especialmente no campo político-partidário -, configurando determinada "cultura da resignação", que contribui para a formação de um caldo político-ideológico. Nesse caldo se assentam as bases do que Coutinho (2010) denominou de "hegemonia da pequena política". Para o autor:

[...] existe hegemonia da pequena política quando a política deixa de ser pensada como arena de luta por diferentes propostas de sociedade e passa, portanto, a ser vista como um terreno alheio à vida cotidiana dos 
indivíduos, como simples administração do existente. A pauta torna-se assim não só um fenômeno de massa, mas é também teorizada como um fator positivo para a conservação da 'democracia' pelos teóricos que condenam o 'excesso de demandas' como gerador de desequilíbrio fiscal e, consequentemente, instabilidade social. (COUTINHO, 2010, p. 32).

Deve-se entender que mesmo nessa ambiência apologética, tão bem apontada acima, faz-se necessário atentar para o risco de se cindirem os elementos que configuram a pequena e a grande política e, assim, trocarem-se os fins pelos meios. Há que se considerar que a pequena política também é expressão da grande política e, portanto, merece ser disputada com projetos contrapostos à ordem hegemônica. Não no sentido de reduzir uma profunda transformação social a um campo imediato e particularista, mas, ao contrário, de disputar o espaço da pequena política, desmascarando seus limites, problematizando-a, saturando-a de elementos da grande política.

Quando o autor faz referência à esfera da política - em seu sentido de grande política - ele a compreende como "passagem do momento meramente econômico (ou egoístico-passional) ao momento ético-político" (GRAMSCI, 2013, p. 314), ou elevação da individualidade à generidade, dos interesses particulares ao conjunto das relações sociais, que, em uma expressão, seria a catarse:

Pode-se empregar a expressão 'catarse' para indicar a passagem do momento meramente econômico (ou egoísmo-passional) ao momento éticopolítico, isto é, a elaboração superior da estrutura em superestrutura na consciência dos homens. Isto significa, também, a passagem do 'objetivo ao subjetivo' e da 'necessidade à liberdade'. A estrutura, de força exterior que esmaga o homem, assimilando-o e o tornando passivo, transformase em meio de liberdade, em instrumento para criar uma nova forma ético-política, em origem de novas iniciativas. A fixação do momento 'catártico' torna-se assim, parece-me, o ponto de partida de toda a filosofia da práxis; o processo catártico coincide com a cadeia de sínteses que resultam do desenvolvimento dialético. (GRAMSCI, 2013, p. 314).

É por meio dessas generalizações que a orientação político-prática, ainda que saturada por determinações iniciais de cunho individual e por estímulos meramente emocionais, se constitui em medium pelo qual a práxis política pode extrapolar o interesse imediato de classe e transformar-se em movimento universal também do ponto de vista social. A tarefa da generalização político-prática parece ganhar contorno mais preciso se conectada com tema aprofundado por Gramsci, qual seja, sua teoria da hegemonia. Para discutir esse elemento, é necessário recorrer a uma contribuição de Gramsci (2013) na relação entre ideologia e política na tradição marxista, ou seja, sua concepção ampliada de Estado.

É justamente na apreensão ampliada de Estado e sua relação com a sociedade civil que Gramsci (2013) expõe a necessidade de (re)com- 


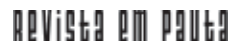

\} IDEOLOGIA E POLÍTICA EM ANTÔNIO GRAMSCI: APROXIMAÇÕES TEÓRICAS - SANTOS, P. R. F. \}

DOI 10.12957/REP.2017.30376

preensão do Estado moderno. Este, em seu sentido ampliado, seria composto por uma sociedade civil e uma sociedade política, que formam a superestrutura, e uma sociedade econômica, que representa a estrutura. Essas três esferas, dialeticamente articuladas, constituiriam a totalidade social.

A sociedade civil se encaixaria entre o Estado e a sociedade econômica. Nessa articulação, "o Estado é o instrumento para adequar a sociedade civil à estrutura econômica" (GRASMCI, 2013, p. 6). Assim, ao considerar a noção delineada por Gramsci (2007, p. 244), tem-se que "na noção geral de Estado entram elementos que devem ser remetidos à noção de sociedade civil (no sentido, seria possível dizer, de que Estado = sociedade política + sociedade civil, isto é, hegemonia couraçada de coerção)".

Cumpre salientar que é um equívoco pensar essas esferas como absolutamente autônomas. O próprio Gramsci (2013) fez essa ponderação. Para o autor, a distinção entre sociedade política e sociedade civil consiste em procedimento metodológico e não orgânico, dado que elas se identificam na realidade dos fatos (GRAMSCI, 2013, p. 21). Ainda que, do ponto de vista analítico, se opere uma distinção entre as esferas, do ponto de vista da totalidade, é impossível separá-las, e, nesse sentido, elas só podem ser apreendidas numa relação dialética de unidade-distinção.

Ao reiterar a dimensão da sociedade política no âmbito dos aparelhos coercitivos ou aparelhos de Estado, Gramsci (2013) avança ao situar, por outro lado, a sociedade civil num movimento dialético de continuidade/ ruptura ou conservação/superação da teoria marxiana clássica, incorporando novos e necessários elementos à sua dimensão, a partir da captura do movimento em que se processam os "aparelhos privados de hegemonia" (COUTINHO, 1999). Entretanto, se existem diferenças entre as análises impressas por Marx e Gramsci, isso não implica distanciamento deste último em relação aos postulados marxianos, na medida em que a linha que vai costurando toda a argumentação gramsciana radica na fidelidade ao método de Marx. O que ocorre é o estudo de "um Estado e um contexto social-histórico saturado de novas determinações inexistentes plenamente no período de Marx" (MONTAÑO; DURIGUETTO, 2011, p. 44). Nessa linha, mais que elaborar uma concepção ampliada de Estado, Gramsci captura do movimento do real essa ampliação. Trata-se da apreensão da realidade elevada à condição de categoria, e não o inverso - o que demonstra a perspicácia desse autor.

Nesse sentido, ainda que para o pensador italiano também haja correspondência entre as esferas econômicas e políticas, e que o Estado seja o espaço no qual se unificam os interesses burgueses, objetivando efetivar seu domínio, seria necessário expor as mediações que dão arquitetura a esse processo. Em Gramsci (2013), tem-se não só um Estado em que se verifica uma esfera repressiva, mas uma luta por hegemonia da burguesia na superestrutura. Essa hegemonia não equivale à mera dominação, mas a uma direção social, impressa pela burguesia, que se legitima sob o consenso dos grupos subalternos. 


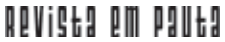

\} IDEOLOGIA E POLÍTICA EM ANTÔNIO GRAMSCI: APROXIMAÇÕES TEÓRICAS - SANTOS, P. R. F. \}

DOI 10.12957/REP.2017.30376

Interessante notar como essa formulação é absolutamente contemporânea, na medida em que a busca por esse consenso se realiza na sua forma mais encarniçada no contexto de crise do capital. Em face da brutal dissonância entre as formas de reprodução da base material e seus discursos político-ideológicos, a burguesia se vê na necessidade de lançar mão de bem articulada trama que possa sustentar as promessas inviáveis do ponto de vista das condições objetivas. Considere-se, por exemplo, todo o discurso em torno da malfadada "cultura da crise", conforme já alertava Mota (2015). Como bem salientou a autora:

Do ponto de vista prático-operativo, emerge a ideia de que na crise, a luta pela preocupação econômica do país beneficia a todos, indistintamente, razão maior do discurso da colaboração e do salvacionismo indiferenciado. Do ponto de vista político, a estratégia adotada tem como consequência o solapamento de um projeto de classe, de corte anticapitalista, mediante a formação de uma vontade política universal que independe da inserção dos sujeitos sociais na estrutura social. (MOTA, 2015, p. 112 grifos nossos).

\begin{abstract}
Assim, é no campo da "hipocrisia proposital" (MARX; ENGELS, 2007) que a burguesia lança mão de intricada rede ídeo-política de forma a consubstanciar a construção de um consenso ativo das classes subalternas, bem aos moldes "não fale em crise, trabalhe" ${ }^{8}$, como forma de unificar esforços indiferenciados de recuperação nacional. Como suporte, recorre-se a um brutal ataque aos trabalhadores, via retirada de direitos historicamente conquistados e/ou em processo de conquista. Para isso, pressupõe a estruturação de determinado "conformismo social", a fim de que se busquem alternativas conjuntas de saída para a crise (MOTA, 2015).
\end{abstract}

Esse conformismo não seria possível sem a possibilidade de ressonância no interior da sociedade civil. Na perspectiva abordada por Gramsci (2013), a sociedade civil é representada pelo conjunto de organismos responsáveis pela elaboração/difusão de ideologias, ou aparelhos privados de hegemonia. Esta compreenderia, assim, as escolas, as igrejas, os partidos políticos, os sindicatos e a organização material da cultura (revistas, jornais, meios de comunicação de massa), entre outros. Citando Gramsci, Simionatto (2011, p. 68) esclarece que a sociedade civil aparece como "o conjunto de organismos 'privados' e que correspondem à função de hegemonia que o grupo dominante exerce sobre toda a sociedade".

Levando-se em consideração sua ampliação da noção de Estado, é impossível dissociar as acepções de ideologia e política, de Gramsci, da sua concepção de hegemonia, sob pena de "amputação" da própria arquitetura do pensamento do autor. Para Brandão e Dias (2007, p. 85), "[...]

\footnotetext{
${ }^{8}$ Conforme recomendou o Presidente do Brasil, Michel Temer, no seu discurso de posse.
} 


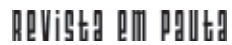

\} IDEOLOGIA E POLÍTICA EM ANTÔNIO GRAMSCI: APROXIMAÇÕES TEÓRICAS - SANTOS, P. R. F. \}

DOI 10.12957/REP.2017.30376

o conceito de hegemonia em Gramsci é de fundamental importância para compreender o que é ideologia, pois se esta última significa uma dada visão de mundo, a primeira trata da construção desta visão". A compreensão é a de que, se a ideologia corresponde a uma dada concepção de mundo, hegemonia corresponde à forma pela qual as classes buscam difundir essa concepção.

Como se relacionam essas duas categorias na obra de Gramsci? Segundo Gruppi (1978, p. 59), a hegemonia corresponde a "[...] tornar-se protagonista das reivindicações de outros estratos sociais, da solução das mesmas, de modo a unir em torno de si esses estratos, realizando com eles uma aliança na luta contra o capitalismo, e desse modo, isolando o próprio capitalismo". Obviamente que isso não significa uma relação dual de convivência de duas estruturas societais no interior do próprio capitalismo, mas implica o fortalecimento de um projeto alternativo a essa sociabilidade, que se possa realizar para e pelo conjunto das classes subalternas e que passa a ser gestado já no interior desse modo de produção.

Por quais mecanismos se articulam ideologia, hegemonia e política na obra de Gramsci? Ao explicitar cada uma dessas categorias, o autor se preocupa, fundamentalmente, com os meios pelos quais é possível construir uma nova vontade coletiva, uma nova correlação de forças que se contraponha à hegemonia dominante. Daí a importância dos aparelhos privados de hegemonia. Todavia, é mister destacar que essas estruturas (aparelhos privados de hegemonia) seriam espaços vazios e abstratos se não se levasse em conta o papel desempenhado pelos sujeitos que as "operam": os intelectuais.

Há que se perguntar: a quem cumpre a função de intelectual? Estaria Gramsci se referindo ao intelectual no sentido stricto da expressão, como o sujeito letrado e com profundo domínio cultural, comumente inserido no meio acadêmico? Não necessariamente. A priori, todos podem desempenar esse papel, pois, para Gramsci (2014, p. 19),

[...] todos os homens são intelectuais, mas nem todos os homens têm na sociedade a função de intelectuais (assim, o fato de que alguém possa, em determinado momento fritar dois ovos ou costurar um rasgão no paletó não significa que todos sejam cozinheiros ou alfaiates). Formam-se assim, historicamente, categorias especializadas para o exercício da função intelectual; formam-se em conexão com todos os grupos sociais, mas, sobretudo em conexão com os grupos sociais mais importantes, e sofrem elaborações mais amplas e complexas em ligação com o grupo social dominante.

Assim, por intelectual deve-se entender não somente essas camadas sociais chamadas tradicionalmente de intelectuais, mas, em geral, "toda a massa social que exerce funções de organização no sentido mais amplo: seja no domínio da produção, da cultura ou da administração pú- 


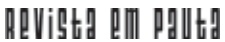

\} IDEOLOGIA E POLÍTICA EM ANTÔNIO GRAMSCI: APROXIMAÇÕES TEÓRICAS - SANTOS, P. R. F. \}

DOI $10.12957 /$ REP.2017.30376

blica" (SIMIONATTO, 2011, p. 61-62). Isso ocorre na medida em que, para Gramsci (2014, p. 16):

Todo grupo social, nascendo no terreno originário de uma função essencial no mundo da produção econômica, cria para si, ao mesmo tempo, organicamente, uma ou mais camadas de intelectuais que lhe dão homogeneidade e consciência da própria função, não apenas no campo econômico, mas também no social e político [...].

Ainda segundo o autor, as camadas de intelectuais poderiam ser agrupadas em dois grandes estratos: os intelectuais tradicionais e os intelectuais orgânicos. Os primeiros corresponderiam "aos intelectuais que sobreviveram ao desparecimento do modo de produção anterior e que não se acham atualmente ligados organicamente a nenhuma das classes fundamentais" (SIMIONATTO, 2011, p. 57-58). Exemplo desse tipo de intelectual corresponde àqueles que formam o clero. O intelectual orgânico corresponde aos estratos que surgem como demanda de difusão das classes que se estruturam como fundamentais num dado modo de produção. São segmentos que compartilham valores e aspirações ideo-políticas da classe à qual se vinculam de forma orgânica. Para ilustrar essa argumentação, Gramsci (2007, p. 315) aponta que "o empresário capitalista cria consigo o técnico da indústria, o cientista da economia política, o organizador de uma nova cultura, de um novo direito etc.".

A difusão da ideologia pelos intelectuais está em manter a direção das classes sociais, os tradicionais , ou, no caso dos orgânicos, em contribuir na manutenção do domínio ou resistência no âmbito das classes subalternas. Além de participar ativamente das relações sociais de produção, como eles são organizadores da função econômica e, simultaneamente, da hegemonia, significa que exercem todo o controle na sociedade civil.

Ademais, é fundamental destacar o papel dos intelectuais na sua dimensão coletiva, no âmbito das organizações que compõem os aparelhos privados de hegemonia. São exemplares desse segmento, sobretudo no contexto contemporâneo, os papéis desempenhados pelos movimentos sociais, sindicatos e pelo estrato mais elevado das organizações coletivas, que é o partido, ou "o moderno Príncipe". Este corresponde à principal mediação capaz de transitar entre as demandas particulares, fincadas no nível socioeconômico corporativo, até uma dimensão ético-política de caráter universal. Em outros termos, o partido seria a organização capaz de propiciar de forma mais significativa o momento catártico. Dialogando com as formulações apresentadas por Maquiavel, Gramsci (2013, p. 16) entendia que:

O moderno príncipe, o mito-príncipe não pode ser uma pessoa real, um indivíduo concreto, só pode ser um organismo; um elemento complexo de sociedade no qual já tenha tido início a concretização de uma vontade coletiva reconhecida e afirmada parcialmente na ação. Este organismo 
já está dado pelo desenvolvimento histórico e é o partido político, a primeira célula na qual se sintetizam germes de vontade coletiva que tendem a se tornar universais e totais.

Ainda que se entenda que o momento exige pensar as debilidades que têm limitado as potencialidades dos partidos de esquerda, que almejam uma transformação social, é preciso compreender que ele(s) ainda permanece $(m)$ como sendo vital(is) na consubstanciação das demandas imediatas, em um amplo projeto que expresse "nova vontade coletiva nacionalpopular" (GRAMSCI, 2013), pela qual se encaminhará forma superior e total de civilização moderna.

Assim como a formulação gramsciana, tem-se a clareza de que esse processo é inviável sem profunda "reforma intelectual e moral", que se expresse em nova cultura, consubstanciada em visão social de mundo radicalmente diferente do modo de produção capitalista. Não se trata, todavia, de uma reforma no sentido abstrato, e sim, necessariamente, de uma que tenha como base as relações sociais de produção que a sustentam. Se a leitura estiver correta, parece que Gramsci (2013) tinha muita clareza acerca dessa necessidade, contrariando qualquer visão, muito em voga, politicista e subjetivista do autor. Para ele: "[...] uma reforma intelectual e moral não pode deixar de estar ligada a um programa de reforma econômica; mais precisamente, o programa de reforma econômica é exatamente o modo concreto através do qual se apresenta toda reforma intelectual e moral" (GRAMSCI, 2013, p. 15 - grifos nossos).

Portanto, amplo panorama de alteração político-ideológica, ainda que absolutamente necessário, implica quadro de alterações na base material que lhe dê sustentação, de modo a congregar novo bloco histórico, articulando estrutura e superestrutura com vistas à construção de outra sociabilidade. Por outro lado, como não são processos isolados, mas que se imbricam, faz-se necessário investir na criação/fortalecimento de uma cultura de resistência, que consiga congregar os mais amplos setores da esquerda numa pauta comum. Além disso, que se estruture uma contraofensiva à hegemonia do grande capital, mais que apenas limitar-se às cada vez mais escassas possibilidades - mas não menos importantes - das lutas defensivas.

É nesses termos que, na obra de Antônio Gramsci, há uma relação indissociável entre as categorias de ideologia e política, tendo como eixo articulador a noção de hegemonia apresentada pelo pensador sardo. Como várias vezes ele mencionou, tudo é atravessado pela política, bem como não há sujeito que não expresse uma dada concepção de mundo. Assim, numa sociedade em que os interesses, imediatos e universais, são atravessados por clivagens de classe, não se podem negligenciar esses interesses, sobretudo se considerada a necessidade de construção de contra-hegemonia que possa elevar os subalternos à condição de classe de dirigente.

Ainda que evitando subjetivismos, entenda-se que aquelas esferas constituem complexos cuja dinâmica não resulta de uma relação direta e 


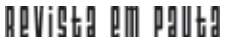

\} IDEOLOGIA E POLÍTICA EM ANTÔNIO GRAMSCI: APROXIMAÇÕES TEÓRICAS - SANTOS, P. R. F. \}

DOI 10.12957/REP.2017.30376

mecânica das alterações das relações sociais de produção, bem como não se pode dissociar ideologia e política da base material que as funda. Por isso, é fundamental a organização política, a construção de uma consciência coletiva e o acúmulo da luta em todas as frentes, de modo a possibilitar a superação dessa forma de sociabilidade.

\section{Considerações finais}

Como se apresentou neste texto, Gramsci capturou com profunda perspicácia a natureza e funcionalidade da materialidade que dá forma à ideologia e à política. A partir de seus fundamentos, o autor demonstrou que, por serem categorias históricas, são saturadas de determinações sociais e perspectivas de classe que, por sua vez, representam interesses antagônicos. Por serem históricas, são passíveis de mudança, o que implica a construção de estratégias no âmbito de uma alternativa contra-hegemônica. Por isso, constituem categorias fundamentais para pensar os desafios e as tarefas contemporâneas.

Os processos de radicalização da empreitada capitalista têm imposto grandes desafios à organização das classes subalternas. Aceleram-se mudanças no plano da base material que, em tempos de aguda crise, manifestam a face mais perversa dessa forma de sociabilidade. Sabe-se que são tempos difíceis; tempos em que o velho - mesmo "cambaleante" - insiste em permanecer e o novo ainda "teima" em não emergir. Mas é preciso assumir o desafio histórico de resistir à ofensiva do capital, fortalecendo as "trincheiras" erguidas na luta cotidiana pelo conjunto dos segmentos subalternos.

A obra do pensador italiano permite problematizar não só a possibilidade, mas, sobretudo, a necessidade histórica da constituição de uma nova vontade coletiva que, forjada nas lutas situadas na produção, espraiese de todos os poros da reprodução social, como campos imbricados. Isso requer o fortalecimento dos espaços na sociedade civil, para que se constitua em "trincheiras" nas quais o conjunto dos trabalhadores possa imprimir uma resistência às ofensivas do capital.

A constituição dessa nova vontade coletiva deve, necessariamente, articular luta ideológica - em sentido gramsciano - e estratégia política na conjugação de espaços e sujeitos que possam levar à frente essa empreitada. Daí a necessidade de fortalecimento dos espaços coletivos - sindicatos, movimentos sociais e partidos políticos -, para que representem proposta programática de ruptura com a ordem vigente e recoloquem na pauta do dia a necessária construção de uma sociabilidade emancipada, de natureza comunista. 


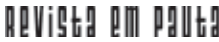

\} IDEOLOGIA E POLÍTICA EM ANTÔNIO GRAMSCI: APROXIMAÇÕES TEÓRICAS - SANTOS, P. R. F. \} DOI 10.12957/REP.2017.30376

\section{Referências}

ANTUNES, R. Adeus ao trabalho? Ensaios sobre as metamorfoses e a centralidade do mundo do trabalho. São Paulo: Cortez, 1998.

BELL, D. O fim da ideologia. Brasília: Editora Universidade de Brasília, 1980. BRANDÃO, N. A; DIAS, E. F. A questão da ideologia em Antônio Gramsci. 2007. Disponível em: <http://www.portal.fae.ufmg.br/seer/index.php/ trabedu/article/viewFile/877/769>. Acesso em: 28 ago. 2015.

COUTINHO, C. N. Gramsci: um estudo sobre seu pensamento político. Rio de Janeiro: Civilização Brasileira, 1999.

. Lukács, a ontologia e a política. In: COUTINHO, C. N. Marxismo e política - a dualidade de poderes e outros ensaios. São Paulo: Cortez, 2008.

A hegemonia da pequena política. In: OLIVEIRA, C.; RIZEK, C. Hegemonia às avessas. São Paulo: Boitempo, 2010.

DIAS, E. F. A política brasileira: embate de projetos hegemônicos. São Paulo: Editora Instituto José Luis e Rosa Sunderman, 2006.

FUKUYAMA, F. O fim da história e o último homem. São Paulo: Roco, 1992.

GRAMSCI, A. Cadernos do cárcere. Vol. 1. Rio de Janeiro: Editora Civilização Brasileira, 2007.

- Cadernos do cárcere. Vol. 3. Rio de Janeiro: Editora Civilização Brasileira, 2013.

- Cadernos do cárcere. Vol 2. Rio de Janeiro: Editora Civilização Brasileira, 2014.

GRUPPI, L. O conceito de hegemonia em Gramsci. São Paulo: Graal, 1978. HARVEY, D. Condição pós-moderna. São Paulo: Loyola, 1998.

IASI, M. Ideologia... quer uma para viver? In: IASI, M. Ensaios sobre consciência e emancipação. São Paulo: Expressão Popular, 2011.

. Alienação e ideologia: a carne real das abstrações ideais. In: Marx e a dialética da sociedade civil. Marilia: Ofício Universitária; Capes; Cultura Acadêmica Editora, 2014.

KONDER, L. A questão da ideologia. São Paulo: Companhia das Letras, 2002.

LIGUORI. G. Roteiros para Gramsci. Rio de Janeiro: Editora UFRJ, 2007.

LUKÁCS, G. O processo de democratização. In: Socialismo e democratização - escritos políticos (1956-1971). Rio de Janeiro: Editora UFRJ, 2011. 


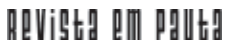

\} IDEOLOGIA E POLÍTICA EM ANTONNIO GRAMSCI: APROXIMAÇÕES TEÓRICAS - SANTOS, P. R. F. \}

DOI 10.12957/REP.2017.30376

LUKÁCS, G. Para uma ontologia do ser social. Vol. 2. São Paulo: Boitempo, 2013.

MARX, K. Prefácio. In: Contribuição à crítica da economia política. São Paulo: Expressão Popular, 2008.

. Introdução. In: Crítica da filosofia do direito de Hegel. São Paulo: Boitempo, 2013.

MARX, K.; ENGELS, F. A ideologia alemã. São Paulo: Boitempo, 2007.

MESZÁROS, I. Para além do capital. São Paulo: Boitempo, 2009.

MONTAÑO, C.; DURIGUETTO, M. L. Estado, classe e movimento social. São Paulo: Cortez, 2011.

MOTA, A. E. Cultura da crise e seguridade social. São Paulo Cortez, 2015.

SIMIONATTO, I. Gramsci - sua teoria, incidência no Brasil, influência no Serviço Social. São Paulo: Cortez, 2011.

Recebido em 27 de junho de 2016.

Aprovado para publicação em 07 de dezembro de 2016.

DOI 10.12957/rep.2017.30376

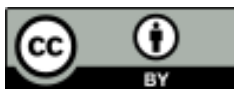

A Revista Em Pauta: Teoria Social e Realidade Contemporânea está licenciada com uma Licença Creative Commons Atribuição 4.0 Internacional. 